\title{
The Paradox around the Social Representations of Compressed Earth Block Building Material in Burkina Faso: The Material for the Poor or the Luxury Material?
}

\author{
Ousmane Zoungrana1,2, Maïmouna Bologo/Traoré1, Adamah Messan', \\ Philbert Nshimiyimana ${ }^{1,3^{*}}$, Gautier Pirotte ${ }^{2}$ \\ ${ }^{1}$ Laboratoire Eco-Matériaux et Habitats Durables (LEMHaD), Institut International d'Ingénierie de l'Eau et de l'Environnement \\ (Institut 2IE), Ouagadougou, Burkina Faso \\ ${ }^{2}$ Laboratoire Observer les Mondes en Recomposition (OMER), Faculté des Sciences Humaines et Sociales, Université de Liège \\ (ULiège), Liège, Belgique \\ ${ }^{3}$ Urban and Environmental Engineering (UEE), Université de Liège (ULiege), Liège, Belgique \\ Email: * pnshimiyimana@doct.uliege.be
}

How to cite this paper: Zoungrana, O. Bologo/Traoré, M., Messan, A., Nshimiyimana, P., \& Pirotte, G. (2021). The Paradox around the Social Representations of Compressed Earth Block Building Material in Burkina Faso: The Material for the Poor or the Luxury Material? Open Journal of Social Sciences, 9, 50-65. https://doi.org/10.4236/jss.2021.91004

Received: November 12, 2020

Accepted: January 11, 2021

Published: January 14, 2021

Copyright $\odot 2021$ by author(s) and Scientific Research Publishing Inc. This work is licensed under the Creative Commons Attribution International License (CC BY 4.0).

http://creativecommons.org/licenses/by/4.0/ (c) (i) Open Access

\begin{abstract}
Compressed earth brick (CEB) is a masonry material which has the thermal properties that are better adapted to the hot and dry climate of tropical and Sahelian context like in Burkina Faso. Despite these advantages, CEB are still not largely used in the construction sector in the city of Ouagadougou. In order to better understand the obstacles linked to this low diffusion of CEB, the present empirical study proposes a deep analysis of the social representations of construction using CEB in the urban place. The results show that four main categories of social representations coexist in the construction sector using CEB: 1) the perception of CEB as the "material for the poor", 2) the perception of $\mathrm{CEB}$ as "improved or precarious adobe" inherited from successive public policies to rehabilitate the material, 3) the symbolic perceptions linked to the red color of the brick and the durability of the material, and 4) the contemporary post-materialist perception (luxury materials), according to a minority of wealthy elites who have built their houses using CEB. These social representations are essential to take into consideration for the implementation of new public housing policies in general and promotion for the usage of CEB in particular. This could accompany the studies which aim at improving the technical performances of CEB and lead towards the socio-economic acceptance of the materials.
\end{abstract}




\section{Keywords}

Autochthony, Burkina Faso, Compressed Earth Bock, Public Policy, Social Representation

\section{Introduction}

In Burkina Faso, a landlocked country with limited resources, banco (construction using adobe: the hand formed and sun-dried earth brick) has long been the most common technique used for housing construction in urban and rural areas (Kéré, 1995). Historically, the city of Ouagadougou was built on the palace-market combination before the creation of the colony in 1919 (Fourchard, 2001). This dominance of the construction technique using adobe brick earned the nickname of "Bancoville" attributed to the city of Ouagadougou during the colonial era (Meyer, 2008; Duperray, 1992).

Nowadays, with a total population of Burkina Faso estimated at 20 million inhabitants, its administrative and political capital Ouagadougou has a population of about 3 million (World Atlas, 2019). Moreover, with an estimated urbanization rate of $32 \%$ in 2016, this rate could reach $40 \%$ by 2025 (UN Habitat, 2014). This urban growth poses many challenges in terms of access to building materials adapted to the climate context for most households. For example, among different wall building materials such as adobe bricks, cement blocks, cut laterite blocks, and compressed earth brick (CEB: the manually or mechanically compressed earth brick using a machine in mold which has regular dimensions and shapes); there is a preference for the use of cement-based materials in the construction sector. In fact, the cement consumption increased by 27\% between 2016 and 2017, with an estimated annual production of 2.5 million ton in Burkina Faso (Sidwaya, 2019). Similarly, in the urban context of Ouagadougou, the constructions made of local materials such as earth-based materials like adobe represent about $47 \%$, against $57 \%$ for the so called hard or semi-hard materials such as cement based materials like cinder blocks and cement plasters (Delaunay \& Boyer, 2017).

During the 1980s and 1990s, public policies were implemented by the state government of Burkina Faso and development partners for the rehabilitation of earth construction in the form of CEB. The two major public policies were: 1) the first implementation of public policy (1984) under the revolution of Thomas Sankara and 2) the second (1994-2011) under the project Locomat (volorization of local materials). This was in order to allow the urban populations to have access to local materials and adapted to extreme climatic conditions (Traoré, 2003). Similarly, many researches have been globally carried out, in the field of science and engineering of earth-based materials, in order to address the constraints related to the durability and improve the properties of non-conventional materials 
such as CEB (Walker, 2004; Fabbri et al.; 2019; Medvey \& Dobszay, 2020).

In the local context of Burkina Faso, similar studies have specifically focused on the stabilization using industrial binders (cement or lime), geopolymer binders, plant fibers or industrial and agricultural by-products in order to enhance the physical and mechanical performances and durability of CEB for applications in building wall constructions (Ouedraogo et al., 2015; Nshimiyimana et al., 2018; Sore et al., 2018; Nshimiyimana et al., 2020a, 2020b, 2020c, 2020d; Nshimiyimana et al., forthcoming). Additionally, a number of studies has assessed the potential of CEBs as masonry material for improving the indoor comfort and potentially reduce the energy consumption for air-conditioning (Hema et al., 2017; Moussa et al. 2019; Hema et al., 2020; Hema et al., forthcoming).

However, only a limited number of studies (Hughes, 2015) has specifically focused on the aspect related to the social perceptions of construction using CEB. Thus, in order to identify local reluctance to the usage of CEB, the present research study seeks to shed new light to the question: what is the influence of social representations on the use of CEB in housing construction in Ouagadougou? This study focused on the analysis of social perceptions of earth constructions using adobe and CEB as masonry materials, in order to study the obstacles towards the adoption of CEB.

\section{Methodology}

This methodological section explains the theoretical framework of reference, the approach and techniques of data collection as well as the analysis strategy of the collected empirical corpuses.

In this study, the theory of social representations was chosen in the analytical framework to study the social perceptions related to the construction using CEB. The choice of this framework is based on the fact that the theory of social representations makes it possible to understand the notions and the conceptions that local actors (architects, clients, owners of houses made of CEB, engineers, technicians, contractors, etc) have of the construction using earth in general or CEB in particular.

This framework of analysis allows producing knowledge at both the individual and collective level on the construction of CEB-based buildings. Indeed, "the concept of social representation designates a specific form of knowledge, common knowledge, whose contents manifest the operation of socially marked generative and functional processes" (Jodelet, 1989). This choice can be explained by the fact that social representations prepare for action and generate normative expectations (Bonardi \& Roussiau, 2014).

This justified the adoption of a qualitative approach in order to identify the logics of perceptions from a socio-anthropological point of view. In this perspective, the interview was chosen as a tool to collect discursive information in order to grasp the local popular indigenous representations, sometimes called "emic", from the point of view of the actors (Olivier de Sardan, 2003, 2008). 
An empirical study was conducted in the city of Ouagadougou between 2017 and 2019. In order to understand the beliefs and opinions built around CEB, semi-directive interview guides were addressed to the following actors: 1) the resource persons (residents), 2) the construction professionals (architects, engineers, technicians, masons, laborers and CEB production companies), 3) the minority of the owners of CEB-houses identified in the city of Ouagadougou, 4) the institutional actors at the ministry of urban planning and housing.

All the data collected were transcribed. A thematic content analysis was adopted for the analysis of the collected data. This choice is justified by the fact that content analysis is based on the principle of inference, which allows the researcher to build knowledge from the inference of the surveys' discourse. For this reason, corpus analysis was consisted of a systematic and objectified treatment of the different messages (Dany, 2016).

\section{Results and Discussions}

The field surveys showed that, from the point of view of the local actors, there are indigenous cultural meanings related to the earth construction (adobe). Thus, before returning to the registers of perceptions related to construction using $\mathrm{CEB}$, it is essential to firstly examine the logics of perceptions contained in the earth construction (adobe).

\subsection{Local Social Representations of Adobe Construction (Banco): "The Cinder Block for the Poor?"}

The field investigations have brought to light that the first register of social representation around the earth brick (adobe) is that of the "cinder block of the poor". In this context, the earth brick construction (Banco) conveys the image of a material of dispossession. This negative image in the Burkinabe context is quite rooted in the forms of belief of the urban population, as earth remains the most widely used indigenous material for housing construction.

The legacy of these mode of construction using adobe in time and space has contributed to a poor image of earth construction. This is indicated by different testimonies collected from different actors interviewed, as highlighted through the following discourse:

"In Ouagadougou, when you build your house in banco, people see you as someone who does not have the means" "Tan moaga soaba nug ka taton poré saoba", resident, interview of 27/06/2019.

In the same way, with regard to this negative perception, the architect asserted that:

"In the mentality of the Burkinabe, clay brick is a material of the poor; for them, you don't have a house when you build your house with clay, they prefer cement construction", Architect, interview of 30/04/2018.

In summary, in this register, banco construction is perceived locally in the 
urban space as a symbol of poverty. The earth for construction is simply a material of necessity that does not allow for the expression of the status of the owner as urbanity. The appropriation of the city by its inhabitants generates their belonging to the city's territory, their "urbanity" (Biehler, 2006).

Moreover, the literal translation of the expression "tan ya nuug ka ta ton poré saoaba" in Moore (language of the Moses) refers to this image of an individual whose hand does not reach the back. This metaphor expresses the idea of an individual who cannot afford to be poor. The first register on the plane (emic) constructed around CEB is that of "material for the poor" which derives its legitimacy from autochthony. However, if the earthen construction (adobe) is generally the work of the poor, it cannot be considered exclusively as a sign of precariousness (Jaglin, 1995). After analyzing the first register of social representation of earthen brick construction (banco), the following section focuses on the analysis of the social perceptions resulting from public policies for the rehabilitation of earthen brick (banco) in the form of CEB.

\subsection{Social Representations Inherited from Public Policies for the Valorisation of CEB}

The discursive field data reveal that the second register of social representations around CEB is that of "precarious" or "improved adobe" material. This logic of perception is based on the inadequacies and legacy of the various successive public policies for the rehabilitation of earthen brick in CEB. One can mention the public policies initiated during the 1980s and 1990s by the State and development partners with a view to enhance the value of earthen construction in Burkina Faso (Decret, 1993). These public policies were designed to encourage the usage of CEB through their massive production and the construction of pilot structures using CEB. In a sense, the aim was to encourage urban populations to adopt $\mathrm{CEB}$ as alternative materials to traditional classical cement-based materials (cinder blocks). However, the surveys and field observations revealed that after the implementation of these different policies, the pilot structures suffered the degradation over time.

These degradations have contributed to exacerbating stereotypes and reinforcing the skepticism of city dwellers towards CEB: It has generated stereotypes and a lack of interest about CEB as construction material among city dwellers. This second level of perception is added to the first level of social representation as the cinder of poor from indigenous communities. The following respondents illustrate this situation as well:

"There was a bad experience of construction in CEB in 1984 at the time of the Revolution [The implementation of the first public policy for the valorization of CEB under the revolution (presidency) of Thomas Sankara (1983-1987)]. The different parameters were not implemented to have quality bricks. This experience made a big impression on people. When we say CEB, people are reluctant. This bad experience makes that people do not adhere to the con- 
struction in CEB" Manager of Brickworks company in CEB, interview of 27/04/2017.

Similarly, in relation to the mixed results and negative stereotypes resulting from the first public policies, a surveyed building engineer once again maintained that:

"People have a bad prejudice against the compressed earth bricks because during the Revolution, compressed earth bricks did not resist much, and there were no good results" Civil Engineer, interview of 31/04/2018.

Moreover, this research shows that, apart from the stereotypes from the implementation of the first public policy (1984), the failure and mixed results of the second public policy (Locomat 1993-2011) contributed towards discrediting the non-conventional materials such as CEB in the Burkinabe context. The triangulation of the data collected shows that the rejection of CEB resulted from the shortcomings in the implementation of public policy. In this regard, one architect stated that:

"There was a time when there was more or less a boom in the CEB sector. There were a lot of entrepreneurs who invested in the production of CEB under the Locomat project. There were works that were executed. These structures have crumbled and clients no longer trust these materials because there was a lot of amateurism (...) Today, when we deal with clients, they are very skeptical when we talk about construction in CEB. Today, the major problem with our customers is that there is a crisis of confidence in the construction using CEB. Our clients are reticent" Architect, interview of $15 / 03 / 2018$.

In summary, the discursive data of our interlocutors highlighted that the legacy of successive public policies for the rehabilitation of the CEB has contributed to the stereotypes and a tarnishing the image of the CEBs in the city of Ouagadougou. The impact of these public policies has generated negative social representations of the CEB. This same observation of inadequacies related to durability and water tightness constraints has been enumerated by other studies during the revolutionary (Asche, 1994) and post-revolutionary eras carried out during the second public policy of valorization of CEB.

In a sense, the inadequacies that have marked the implementation of these different public policies are grafted onto the negative representations as the material of the poor inherited at the local level (section 3.1). However, the combination of these first two levels of social representation has contributed towards legitimizing a new form of shared social representations around construction in CEB. This aspect will be developed in the next section.

\subsection{Shared Social Representations around Construction Using CEB and Adobe}

Through empirical field data, it emerges that the shared representations around 
construction using CEB are similar to those attributed to construction using clay bricks (adobe) at the local level. Since construction using CEB is at the interface of traditional and modern construction cultures (Figure 1(a) \& Figure 1(b)), there is a similarity in the social representation of CEB and adobe. The information collected highlights that the obstacles to the acceptance of CEB in the construction are linked to the perceptions that the populations or clients have of the material. The discourse collected from construction professionals converges on the fact that the logic of shared perceptions around CEB and adobe.

"People have difficulty adhering to construction using CEB because in the mentality of the population, the CEB are more traditional. If you build your house in CEB, people see you as a poor guy who does not have the money for cement. That is a bit of a problem", Site foreman of a construction site in CEB, interview of 17/06/2017.

This perception of CEB as a material for the poor is also relayed by a contractor, when he states:

"The symbol is that people want hard [stronger] materials. Local materials such as CEB are perceived as the material for poor people." Contractor, interview of $31 / 01 / 2018$

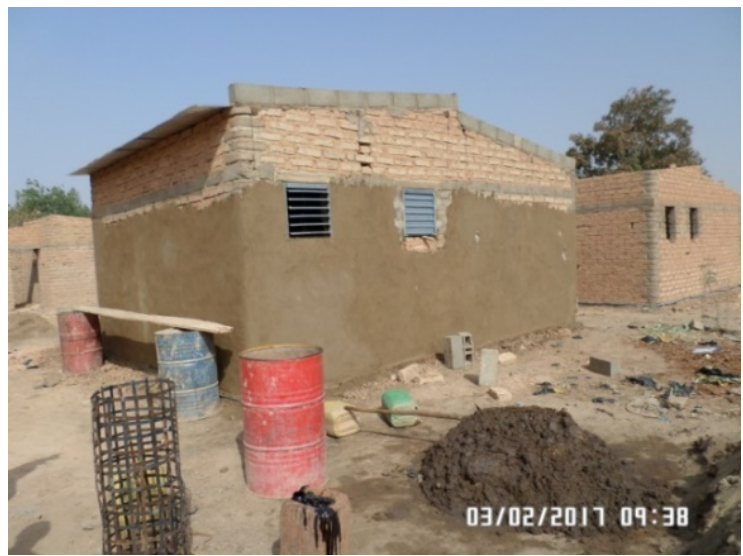

(a)

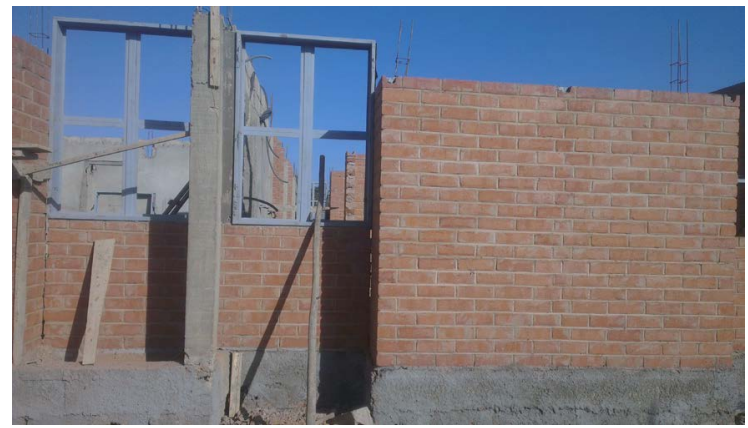

(b)

Figure 1. Construction of house whose walls are made of earth bricks: (a) Adobe brick with cladding, (b) CEB, Ouagadougou, Burkina Faso. 
In the same way, this widely held perception of associating construction using CEB with that of the "cinder block for the poor" is also underlined by an architect, when he states:

"I tend to propose CEB to my clients, but let us just say that many do not accept it. They say that it is indeed the CEB. But in the minds of a lot of people it is still the earth [...]. There is a social weight on these materials. It is not easy, eh! It is the mentality" Architect, interview of 26/04/2018

Briefly, according to the discourse of construction professionals, the shared social representations of CEB remains that of the "cinder block for the poor". Similar studies in Zambia have also highlighted that urban dwellers associate earthen architecture with a connotation of unsustainable, archaic and poverty (Baiche et al., 2008). Also, in other context such as India, a study has shown that earthen construction in rural areas is also considered as a low-status material (Kulshreshtha et al., 2019).

\subsection{Social Representation Related to the Symbolism of the Red Color of the CEB}

In addition to the social perceptions related to indigenousness, public policies and shared representations around the CEB and adobe, this study also revealed another form of perceptions. It is a symbolic perception related to the red color of the CEB. In this register, the image associated with the CEB refers to: "tậnkoeem miugu" (red brick), in Moore language of the Mosse, contains within this ethnic group a singular meaning. The discourse collected from two owners of houses constructed with CEB shows that the symbolism linked to the red color of the material constitutes a barrier to the acceptance of CEB as building masonry (Figure 1(b)). In this regard, here is what one owner of house in CEB affirms:

"Well, it is true that my wife did not want red bricks, because red does not look too pretty. She was worried about this, but the managers of the CEB production company told me that I could put paint or plaster inside the house." Owner of a CEB house, Burkinabe, Master's Degree, interview on April 31, 2018.

These forms of beliefs and conceptions related to color is a source of rejection of the CEB. This form of representation draws its legitimacy from popular conceptions of the symbolism associated with red. As a reminder, Burkina Faso is a multi-ethnic country where more than sixty cultural groups live or cohabitate. Among this diversity are the Mosse, who make up more than $50 \%$ of the population (Nyamba, 2001). In the Burkinabe context, at the cultural level among the Moose, there is a cultural significance linked to the symbolic dimension of the red color of objects. In the socio-cultural anchoring of the Mosse, "miugu" (red) refers to an evil color-revenge. In many royal courts, it is forbidden to approach if one is wearing red, and the red-evil association is extremely alive in all circles. 
It is, for the Mosses, the color of war and blood (Dévérin, 2004).

Similarly, according to the speech collected from a French expatriate who built his house in CEB in Ouagadougou, the symbolism related to the color nature of the land was an obstacle he encountered in the course of his construction project. Behind the expression that he wanted a CEB of "clear" color, also shows that the effects related to the color are an obstacle to the adoption of the CEB. With regards to the symbolism of the color, here is what the French expatriate said:

"It is interesting to build using CEB because the land is available. But, the other weak point is the color of the earth, there are many different colors. At the beginning, I was a little embarrassed because I wanted a relatively light-colored earth (....) and, it was necessary to look a little far in another quarry [for collecting the earthen materials], because among the lots of proposed quarries none suited me. We had to send these different lots of quarry back. That also raises the problem of particular exchanges on the color of the earth". Expatriate, level of education: Medical doctor, interview of $27 / 07 / 2017$.

In summary, cultural factors such as the red color also influence the acceptance of CEB in the Burkinabe urban context. These results reinforce the findings of other studies which showed that the use of colors in architecture are influenced by culture, heritage context, climatic conditions in countries such as Iran or Australia (Motamed \& Tucker, 2016, 2019).

\subsection{Social Representations Related to the Lack of the Durability of CEB}

In this section, the social representations around the material is part of a continuum where CEB is perceived as a non-durable material, against sustained environmental constraints. Construction with $\mathrm{CEB}$ is not perceived, by urban dwellers, as solid in the same way as cement blocks. From this point of view, actors in the construction field maintain that the barriers related to the acceptance of CEB remain linked to the perception related to the lack of durability. The discourses expressed by these two respondents are consistent with this view:

"Here in Ouagadougou, if you tell someone to build with CEB, he will say that it is earthen materials and it is not reliable", Technician in the field of civil engineering, interview of $10 / 07 / 2017$.

"The citizen always has this idea that building with earth or CEB is not a way to build sustainably", Architect, interview of 06/06/2019.

These speeches are corroborated by an official who works in CEB production who maintains that:

"The Burkinabe do not believe in building with earth because they say that CEB is a local product. In the city, people do not trust construction using CEB. When we offer CEB to our clients, they tell us that CEB construction 
is unreliable because it is earth mixed with cement: they prefer cement one hundred percent", Head of CEB production company, interview of 12/04/ 2018.

According to the above discourses, in the perception schemes, construction using CEB does not offer guarantee in terms of longevity or durability. In this register, the CEB is not apprehended as a material that allows for long-term or definitive investment. Similar research in seventeen African countries, including Burkina Faso, has also shown that although earthen construction is generally cheaper and offer more thermal comfort, the low durability and low resistance are the main reasons for its low adoption in African cities (Adegun \& Adedeji, 2017).

After analysing the social representations which are unfavorable to the acceptance of $\mathrm{CEB}$, the following section focuses on an analysis of a positive postmaterialist perception of some owner of dwellings built with CEB.

\subsection{Post-Materialistic Representations of Construction Using CEB}

The field surveys also showed that a minority of city dwellers (Burkinabe, expatriates, and mixed couples) have opted to build their homes using CEB, despite the unfavorable perceptions of CEB. The data collected from this minority of the population revealed a new logic of post-materialism perception. As argued (Inglehart, 1977), post-materialist values are new values of autonomy and self-expression linked to the satisfaction of material needs for security.

First of all, it emerges that this new construction trend using CEB is the work of a minority of an urban elite who have a very high economic and cultural capital. Among this minority, this mode of construction is based on a post-materialist perception of CEB construction. Beyond the functionalities that surround the construction using $\mathrm{CEB}$, there are specific perception logics associated with the construction using CEB. Thus, a closer look at the corpus of owners of CEBhouses shows that construction refers to at least four (04) categorizations of representations around an ecological reasoning.

Finally, in this register, the construction using CEB refers to a positive vision at the individual level of this minority. This is why, according to the point of view of the owners of CEB houses, the words associated with CEB are: 1) a material adapted to the "climatic context" of the Sahelian type, 2) a material that limits the "transmission" of heat and provides thermal comfort to the occupants, 3) a less "energy consuming" material that helps to reduce the electricity bill, 4) a material that makes it possible to achieve "bioclimatic" and/or sustainable constructions, as opposed to the conventional cement-based materials such as cinder blocks. The following discursive information express this form of representation:

"I decided to build using CEB because I realized that the city of Ouagadougou is in a climatic zone that is a bit complicated (...). We tried to adapt the construction to the surrounding climate. The CEB was chosen for its insu- 
lating properties, particularly the delay in the transmission of heat inside the buildings during the day. These are bioclimatic reasons that really motivated me to build using CEB in order to limit as much as possible the heat in the rooms of my house", Owners of housing in CEB, Expatriate, $\mathrm{PhD}$ Degree, interview of 27/07/2017.

The former is joined by another Burkinabe house-owner who says:

"I built my house using CEB because, in terms of climate, it is a type of material that allows you to live in a standard climate because it is not too hot or too cold inside the house", Owner of CEB-house, Burkinabe, Master's Degree, interview of 29/07/2019.

In addition to the adaptation of materials to the Sahelian climate, the perceptions regarding the reduction of electricity bills are embedded in the logic of perceptions regarding construction using CEB. This is supported by an expatriate in these terms:

"I chose to build using CEB to take the climate into account and reduce the cost of the electricity bill. For Sahelian countries such as Burkina Faso, it goes without saying that $\mathrm{CEB}$ would already reduce energy bills in the house", Owner of CEB-house, Expatriate, mixed couple, Master's Degree, interview of 05/09 2019.

In a hot climate such as Burkina Faso, a study showed that thermal discomfort varied according to the walls and spaces of the buildings. The study shows that the construction of CEB walls with very specific criteria would reduce the annual overheating in the rooms of the building (Hema et al., 2020). Similarly, a simulation study also showed that there is a gain in terms of energy savings in house built with a by-product-stabilized CEB, compared to a cinder block-house (Moussa et al., 2019).

In sum, while CEB construction is halfway between traditional and modern building cultures, the owners of CEB housing in the Burkinabe context have a more positive perception of the material. This has been already pointed out in a recent study: the particular way of house construction using CEB by the fraction of population in Ouagadougou integrates the current logic of sustainability in the construction sector (Zoungrana et al., 2020). This same finding is also highlighted in a similar study conducted in North Carolina, Piedmont, which showed that the contractors who had experienced with CEB have a positive perception than those without the prior experience of CEB (Hughes et al., 2017).

However, the present research highlights a shift towards new types of perceptions insofar as the knowledge of the users in the present case study is based on post-materialist perceptions of construction using CEB. This form of perception transcends the first forms of perceptions of "cinder block for the poor" resulting from autochthony and the failure of the public policies for the rehabilitation of earthen construction. Therefore, this research raises new questions: How is a 
material described as "cinder block for the poor", is used by people from wealthy backgrounds? In a sense, for this minority with high cultural and economic capital, the construction using the non-conventional materials such as CEB does not have the pejorative connotation of a cinder block for the poor. CEB is perceived in this context as a luxury material adapted to the climatic context of the Sahelian type.

\section{Conclusion}

This paper has shown that the contemporary resistance to the diffusion of CEB in Ouagadougou can be explained by the aggregation of four (04) registers of interconnected social representations:

1) The representation of CEB as "the cinder block for the poor" resulting from the autochthony of "Bancoville".

2) The representations of CEB as "the improved or precarious banco" resulting from different public policies followed by the rehabilitation of adobe earth brick in the form of CEB, which was carried out by the government in the sector.

3) The symbolic perceptions related to the red color of the CEB and

4) The symbolic perceptions related to the durability over the time of the material.

Therefore, in the urban context of Burkina Faso, the CEB is still perceived as a dispossessed material.

Moreover, the analysis of this research has highlighted the paradox in the field of local materials based on CEB in the urban context of Ouagadougou. This paradox can be explained by the fact that despite the perception as the materials for poor, the construction of house using CEB is the work of a minority of the urban elite (expatriates, mixed couples, Burkinabè) who has high cultural and economic capital. For this minority of users, the construction using CEB is based on an ecological reasoning, based on the break with all-in-concrete (need for alternative and low polluting resources) in the construction of their houses. This ecological reasoning is also based on the post-materialist perceptions (need for less energy-consuming materials, need for comfort) in relation to the sustainable housing advocated by the $11^{\text {th }}$ objective of the sustainable development goals.

In short, taking into account these registers of social representations is an essential path in the implementation of new public housing policies. This case study carried out in Burkina Faso can be carried out in other developing countries by considering the socio-historical and cultural context of the concerned countries. From the above, this study suggests that beyond the studies aiming at finding solutions to improve the physical and mechanical and durability performances (resistance to erosion and degradation), the barriers related to social perceptions should also be considered in order to promote a better acceptance of $\mathrm{CEB}$ in the construction sector.

In view of the results from this study, following specific recommendations can be addressed to the public authorities and the actors of the construction sector 
(producers of CEB, architects, masons, technicians etc.), in order to encourage a new reconquest of the material by the populations in the construction of house:

1) Considering that social factors influence the use of CEB in the urban context. The people's perceptions of objects (CEB materials) are rooted in the social context, and the beliefs of the CEB as the "materials for poor" are socially constructed, and the failure of the public policies to valorize CEB reinforced the rejection of the material.

2) A better supervision of the actors of the sector (producers of CEB) in order to control the stabilization processes with a view to limiting the effects of water degradation that generate prejudices on the durability of the material. The production quality should be assured in order to limit the bad practices inherited from the previous public policies of valorization of CEB. In this perspective, the quality of CEB should comply with the defined standards such as (Abnorm, 2009). These initiatives can be put in place in concertation with research centers and testing laboratories whose results can be used for a better design and stabilization of CEB.

\section{Acknowledgements}

“Académie de Recherche et de l'Enseignement Supérieur" of the "Fédération Wallonie-Bruxelles (Belgium)-Commission de la Coopération au Développement" (ARES-CCD) provided the financial support as part of an international research and development project "Amélioration de la qualité de l'habitat en terre crue au Burkina Faso/Improving the quality of earth based habitat in Burkina Faso (PRD2016-2021).

\section{Conflicts of Interest}

The authors declare no conflicts of interest regarding the publication of this paper.

\section{References}

Abnorm (2009). NBF02-005 :2009: Blocs de Terre Comprimée. Code de bonnes pratiques pour la production des en blocs de terre comprimée. Burkina Faso: Association Burkinabè de normalisation.

Adegun, O. B., \& Adedeji, Y. M. D. (2017). Review of Economic and Environmental Benefits of Earthen Materials for Housing in Africa. Frontiers of Architectural Research, 6, 519-528. https://doi.org/10.1016/j.foar.2017.08.003

Asche, H. (1994). Le Burkina Faso contemporain, l'expérience d'un auto-développement. Paris: L'Harmattan.

Baiche, B., Osmani, M., \& Hadjri, K. (2008). Attitudes towards Earth Construction in the Developing World: A Case Study (pp. 1-8). CIB W107 Construction in... (January).

Biehler, A. (2006). Renouveau urbain et marginalisation. Le cas d'habitants du centre-ville la ville de Ouagadougou-Burkina Faso. Revue Tiers Monde, 1, 58-78. https://doi.org/10.3917/rtm.185.0057

Bonardi, C., \& Roussiau, N. (2014). Les représentations sociales. Paris: Dunod. 
Dany, L. (2016). Analyse qualitative de contenu des représentations sociales. In G. Lo Monaco, G. S. Denouvée, \& P. Rateau (Eds.), Les représentations sociales. Théories, Méthodes et applications (pp. 86-102). Belgique: Louvain La Neuve.

Decret (1993). N'93-166/PRES/PM/TPHU, Décret portant Création et attribution du Projet de recherche d'expérimentation et de vulgarisation des Matériaux Locaux. Burkina Faso: LOCOMAT.

Delaunay, D., \& Boyer, F. (2017). Habiter Ouagadougou Habiter Ouagadougou. Monographies Sud-Nord, $\mathrm{N}^{\circ} 5$.

Dévérin, Y. (2004). Facteurs culturels et représentations de l'espace en pays mossi. In S. Dulucq, \& P. Soubias (Eds.), L'espac public et ses représentations en Afrique subsaharienne. Approche pluridisciplinaire (pp. 15-32). Paris: Karthala.

Duperray, A. (1992). La Haute-Volta (Burkina Faso). In cathérine Coquery Vidrovitch (Ed.), L'Afrique occidentale au temps des français colonisateurs (1860-1960) (pp. 251288). Paris: La Découverte.

Fabbri, A., Soudani, L., McGregor, F., \& Morel, J. C. (2019). Analysis of the Water Absorption Test to Assess the Intrinsic Permeability of Earthen Materials. Construction and Building Materials, 199, 154-162.

https://doi.org/10.1016/j.conbuildmat.2018.12.014

Fourchard, L. (2001). De la Ville Coloniale à la Cour Africaine, Espaces, pouvoirs et sociétés à Ouagadougou. Paris: L'Harmattan.

Hema, C. M., Van Moeseke, G., Evrad, A., Courard, L., \& Messan, A. (2017). Vernacular Housing Practices in Burkina Faso: Representative Models of Construction in Ouagadougou and Walls Hygrothermal Efficiency. In Energy Procedia (Vol. 122, pp. 535540). Lausanne: Elsevier. https://doi.org/10.1016/j.egypro.2017.07.398

Hema, C., Messan, A., Lawane, A., \& Van Moeseke, G. (2020). Impact of the Design of Walls Made of Compressed Earth Blocks on the Thermal Comfort of Housing in Hot Climate. Buildings, 10, 157. https://doi.org/10.3390/buildings10090157

Hema, C., Soro, D., Nshimiyimana, P., Lawane, A., Messan, A., \& Van Moeseke, G. (Forthcoming). Improving the Thermal Comfort in Hot Region through the Design of Walls Made of Compressed Earth Blocks: An Experimental Investigation. Journal of Building Engineering.

Hughes, E. G. (2015). Assessing the Perception of Compressed Earth Block (CEB) among Contractors in the Piedmont Region of North Carolina. Msc Thesis, Fort Collins, CO: The Colorado State University.

Hughes, E., Valdes-Vasquez, R., \& Elliott, J. W. (2017). Perceptions of Compressed Earth Block among Residential Contractors in North Carolina: An Exploratory Evaluation. Journal of Green Building, 12, 89-107. https://doi.org/10.3992/1943-4618.12.4.89

Inglehart, R. (1977). The Silent of Revolution, Changing Values and Political Styles among Western Publics. Princeton, NJ: Princeton University Press.

Jaglin, S. (1995). Gestion urbaine partagée à Ouagadougou. Pouvoirs et périphéries (19831991). Paris: Karthala-O.

Jodelet, D. (1989). La représentation sociale: Phénomènes, concept et théorie. In Moscovici, Psychologie sociale (pp. 361-382). Paris: Presse Universitaire de France.

Kéré, B. (1995). Architecture et cultures constructives du Burkina Faso. Mémoire. CEAA Terre de L'Ecole d'Architecture de Grenoble.

Kulshreshtha, Y., Vardon, P. J., Mota, N. J. A., Loosdrecht, V., \& Jonkers, H. M. (2019). A Case Study on Technical and Social Aspect of Earth Houses in Rural India. In B. V. Venkatarama Reddy, M. Monto, \& P. Walker (Eds.), Earthen Dwellings and Structures 
(pp. 105-115). Berlin: Springer. https://doi.org/10.1007/978-981-13-5883-8 10

Medvey, B., \& Dobszay, G. (2020). Durability of Stabilized Earthen Constructions: A Review. Geotechnical and Geological Engineering, 38, 2403-2425. https://doi.org/10.1007/s10706-020-01208-6

Meyer, P.-E. (2008). De Bancoville à la Ville moderne. In Ouagadougou (1850-2004). Une urbanisation différenciée (pp. 25-37). Marseille: IRD Edition. https://doi.org/10.4000/books.irdeditions.892

Motamed, B., \& Tucker, R. (2016). The Etymology of a Colourful Design Language: How Do We Determine What Informs Architect's Colour Choices? Art, Design and Communication in Higher Education, 15, 191-208. https://doi.org/10.1386/adch.15.2.191 1

Motamed, B., \& Tucker, R. (2019). Rose Tinted Spectacles: Culturally Informed Differences between Iran and Australia in Architect's Colour Cognition, Preference and Use. City, Culture and Society, 18, Article ID: 100288. https://doi.org/10.1016/j.ccs.2019.05.004

Moussa, S. H., Nshimiyimana, P., Hema, C., Zoungrana, O., Messan, A., \& Courard, L. (2019). Comparative Study of Thermal Comfort Induced from Masonry Made of Stabilized Compressed Earth Block vs Conventional Cementitious Material. Journal of Minerals and Materials Characterization and Engineering, 7, 385-403. https://doi.org/10.4236/jmmce.2019.76026

Nshimiyimana, P., Fagel, N., Messan, A., Wetshondo, D. O., \& Courard, L. (2020a). Physico-Chemical and Mineralogical Characterization of Clay Materials Suitable for Production of Stabilized Compressed Earth Blocks. Construction and Building Materials, 241, 1-13. https://doi.org/10.1016/j.conbuildmat.2020.118097

Nshimiyimana, P., Hema, C., Zoungrana, O., Messan, A., \& Courard, L. (2020d). Thermophysical and Mechanical Properties of Compressed Earth Blocks Containing Fibres: By-Product of Okra Plant \& Polymer Waste. WIT Transactions on the Built Environment, 195, 149-161. https://doi.org/10.2495/ARC200121

Nshimiyimana, P., Messan, A., \& Courard, L. (2020b). Physico-Mechanical an Hygro-Thermal Properties of Compressed Earth Block Stabilized with Industrial and Agro By Products Binders. Matérials, 13, 37-69. https://doi.org/10.3390/ma13173769

Nshimiyimana, P., Messan, A., \& Courard, L. (forthcoming). Hydric and Durability Performances of Compressed Earth Blocks Stabilized with Industrial and Agro By-Product Binders: Calcium Carbide Residue and Rice Husk Ash. Journal of Materials in Civil Engineering.

Nshimiyimana, P., Miraucourt, D., Messan, A., \& Courard, L. (2018). Calcium Carbide Residue and Rice Husk Ash for Improving the Compressive Strength of Compressed Earth Blocks. MRS Advances, 3, 2009-2014. https://doi.org/10.1557/adv.2018.147

Nshimiyimana, P., Moussa, H., \& Messan, A. (2020c). Effect of Production and Curing Conditions on the Performance of Stabilized Compressed Earth Blocks: Kaolinte vs Quartz-Rich Earthen Material. MRS Advances, 5, 1277-1283. https://doi.org/10.1557/adv.2020.155

Nyamba, A. (2001). Les relations de plaisanteries au Burkina Faso. Open Edition Journal, 21, 119-140. https://doi.org/10.4000/communication.5503

Olivier de Sardan, J. P. (2003). L'enquête socio-anthropologique de terrain: Synthèse méthodologique et recommandations à usage des étudiants.

Olivier de Sardan, J.-P. (2008). La rigueur du qualitatif, Les contraintes empiriques de l'interprétation socio-anthropologique. Belgique.

Ouedraogo, E., Coulibaly, O., Ouedraogo, A., \& Messan, A. (2015). Caractérisation mécanique et thermophysique des blocs de terre comprimée stabilisée au papier (cellulose) 
et/ou au ciment. Journal of Materials and Engineering Structures, 2, 68-76.

Sidwaya (2019). Production de ciment: Cim-Burkina double sa production avec un nouveau broyeur $\left(\mathrm{N}^{\circ} 8920\right.$, p. 25).

Sore, S. O., Messan, A., Prud'homme, E., Escadeillas, G., \& Tsobnang, F. (2018). Stabilization of Compressed Earth Blocks (CEBs) by Geopolymer Binder Based on Local Materials from Burkina Faso. Construction and Building Materials, 165, 333-345.

https://doi.org/10.1016/j.conbuildmat.2018.01.051

Traoré, A. (2003). La problématique des matériaux locaux de construction dans le développement du logement à Ouagadougou. Master's Thesis, Burkina Faso: The Université de Ouagadougou.

UN Habitat (2014). L'état des villes Africaines. Réinventer la transition urbaine (The State of African Cities). Nairobi.

Walker, P. J. (2004). Strength and Erosion Characteristics of Earth Blocks and Earth Block Masonry. Journal of Materials in Civil Engineering, 16, 497-506.

https://doi.org/10.1061/(ASCE)0899-1561(2004)16:5(497)

Zoungrana, O., Bologo Traoré, M., Hema, C., Nshimiyimana, P., Pirotte, G., \& Messan, A. (2020). Sustainable Habitat in Burkina Faso: Social Trajectories, Logics and Motivations for the Use of Compressed Earth Blocks for Housing Construction in Ouagadougou. WIT Transactions on the Built Environment, 195, 165-172.

https://doi.org/10.2495/ARC200131 